\title{
ELEIÇÃO E MÍDIA: UMA ANÁLISE EMPÍRICA DA COBERTURA ELEITORAL DO PORTAL ELETRÔNICO DO JORNAL GAZETA DO POVO NA ELEIÇÃO À PREFEITURA DA CIDADE DE CURITIBA, ANO 2012
}

\author{
Anne Caroline Pellizzaro ${ }^{1}$ \\ Laura Sloboda Lopes ${ }^{2}$
}

\begin{abstract}
Resumo
Os meios de comunicação desempenham papel fundamental na sociedade contemporânea, já que constituem um espaço capaz de promover o debate público e propagar, simultaneamente, conhecimentos múltiplos sobre um mesmo conflito. Atuam também como mediadores em períodos de Campanha Eleitoral por possuírem o alcance eficaz na transmissão do quadro formado por candidatos e propostas, no período que antecede o pleito. Considerando a demanda por informações progressivamente mais ágeis e globalizadas, a internet representa uma nova dinâmica no repasse de notícias. Desta forma, o objetivo do presente artigo é analisar esta nova relação entre mídia e política e qual seu modelo. Logo, pretende-se responder as seguintes perguntas: Qual a cobertura feita pelo Portal Gazeta do Povo durante o período eleitoral? Qual a visibilidade dos principais candidatos à prefeitura no portal? A hipótese é que o espaço dado aos candidatos é distinto, porém equilibrado. O método aqui presente é o quantitativo, sendo utilizados como parâmetros para a pesquisa os meses de julho a outubro de 2012. Os resultados demonstram que houve 378 postagens contendo ao menos o nome de um dos três principais candidatos às eleições municipais para o cargo de Prefeito.
\end{abstract}

Palavras-chave: Comunicação Política, Eleições Municipais, Curitiba, Mídia Digital.

\begin{abstract}
Resumen
Los medios de comunicación desempeñan un papel crucial en la sociedad contemporánea, ya que constituyen un área capaz de promover el debate público y propagar el conocimiento de forma simultânea en una disputa particular. Además de actuar como mediadores en los períodos de campaña electoral por tener el alcance efectivo de la transmisión de la trama formada por los candidatos y propuestas, en el período previo a la elección. Teniendo en cuenta la demanda de información cada vez más flexible y globalizado, Internet es una nueva dinámica en la emisión de noticias. Por lo tanto, el objetivo de este trabajo es analizar esta nueva relación entre los medios y la política y cuál es su modelo. Por lo tanto, tenemos la intención de responder a las siguientes preguntas: ¿Cuál es la cubierta hecha por Gazeta do Povo Portal durante el periodo electoral? ¿Cuál es la visibilidad de los principales candidatos a la alcaldía en el portal? La hipótesis es que el espacio dado a los candidatos es distinto, pero equilibrado con sus colocaciones finales. La metodología es cuantitativa, utilizando como parámetros los meses de julio a octubre de 2012. Los resultados muestran que hubo 378 posts que contengan por lo menos el nombre de uno de los tres principales candidatos en las elecciones municipales para el cargo de Alcalde.
\end{abstract}

Palabras clave: Comunicación política, Elecciones Municipales, Curitiba, Medios Digitales

\footnotetext{
1 Mestranda pelo Programa de Pós-Graduação em Ciência Política da UFPR. Pesquisadora do grupo de Comunicação Politica e Opinião Pública - CPOP.

2 Graduanda em Ciências Sociais pela Universidade Federal do Paraná. Pesquisadora do grupo de Comunicação Politica e Opinião Pública - CPOP e do Núcleo de Pesquisas em Relações InternacionaisNEPRI.
} 


\begin{abstract}
The media are crucial in contemporary society, as they are capable of intermediate public debate and simultaneously propagate multiple knowledge on any dispute. Also act as mediators in periods of Electoral Campaign by introducing the candidates and their proposals in the period preceding the election. Considering the increasingly demand for flexible and globalized information, the Internet means a new dynamic in the transmission of news. Thus, the aim of this paper is to analyze this new relationship between media and politics and how it works. Therefore, we intend to answer the following questions: What was the cover made by Gazeta do Povo Internet Portal during the election period? What is the visibility of the main candidates for mayor in that same portal? The hypothesis is that the visibility given to candidates is distinct but justifiable. The methodology utilized in this research was quantitative, and the parameters was set betwen July and October, 2012. The final results indicated that there were 378 posts containing at least the name of one of the three main candidates in the municipal elections for the Mayor role.
\end{abstract}

Keywords: Political Media, Municipal Elections, Curitiba, Digital Media

\title{
1. INTRODUÇÃO
}

Os meios de comunicação constituem uma ferramenta indispensável na sociedade atual, capaz de promover um intenso debate no espaço público, propiciando as trocas de informações para o alcance de todos, suprimindo as barreiras geográficas, culturais e linguísticas. Através destes mecanismos faz-se possível o acesso a diversas informações, das mais variadas, compreendendo desde temas como cultura, lazer, educação, segurança, esportes, economia, cidades até política. Neste último interessa compreender o que os meios representam e quais efeitos a mídia pode produzir nas pessoas. Sua relação direta com o âmbito político, sobretudo os democráticos, também traz questionamentos e discussões motivadores de grandes produções.

Nas democracias a relação entre os meios de comunicação de massa (mass media) e a opinião pública é crucial para se entender como se definem as agendas temáticas, noção que se iniciou nos anos 70 pelos pesquisadores americanos McCombs e Shaw com um modelo de pesquisa desenhado para testar empiricamente os efeitos da comunicação de massa na preferência política e eleitoral do público (AZEVEDO, 2004), e as questões públicas relevantes (MANIN, 1995). O modelo da agenda-setting, a exemplo de outras proposições analíticas, foi uma das respostas dada à problemática dos efeitos, sob as novas exigências teóricas impostas pelo ambiente midiático contemporâneo (AZEVEDO, 2004). O eleitor, através de meios de comunicação neutros, adquire informações políticas importantes, dando a elas seus juízos particulares (MANIN, 1995). 
Destarte, os meios de comunicação são tanto o principal canal de acesso dos cidadãos às informações de que precisam para agir na esfera política quanto o principal instrumento dos líderes políticos para a divulgação de suas mensagens, projetos, temas para a agenda pública, em suma, para a batalha política crucial, a construção de vontades coletivas (ou, dito de outra maneira, a luta pela hegemonia). Isto coloca a mídia numa posição central na arena política das sociedades contemporâneas (MIGUEL, 2000, p. 66/67).

O objeto desta pesquisa é, portanto, a análise da cobertura eleitoral feita pelo Portal Gazeta do Povo em relação aos três principais candidatos da disputa, Luciano Ducci (PSB), Gustavo Fruet (PDT) e Ratinho Jr. (PSC), no período de julho a outubro de 2012. A escolha destes candidatos se justifica em razão do Luciano Ducci ser candidato à reeleição e os candidatos Gustavo Fruet e Ratinho Junior apresentarem durante toda a campanha índices altos de preferência nas pesquisas de opinião. Foram contabilizados neste período 378 postagens.

A problematização consiste na formulação das seguintes perguntas: Quais os temas agendados no portal eletrônico? Qual a visibilidade dos candidatos no portal eletrônico? Há diferenças entre a visibilidade e valência dos candidatos na tratativa do portal?

A hipótese principal desta pesquisa é que o portal Gazeta do Povo no que tange a cobertura eleitoral fornece um espaço distinto aos candidatos da disputa, mas equilibrado com o espaço que os mesmos têm posteriormente nas colocações eleitorais que conquistam.

Para referendar a pesquisa é utilizado o método quantitativo de análise de conteúdo A escolha deste método se justifica ante a necessidade de correlacionar quantitativamente os dados coletados no portal e por se tratar de um universo grande (378 posts). O que se tem a seguir é, então, uma análise interpretativa dos dados coletados, uma expressão do que fora a cobertura eleitoral do Portal da Gazeta do Povo em 2012.

Opta-se pelo meio de comunicação digital porque a internet integra as novas tecnologias de informação e comunicação (NTIC), constituindo-se como uma importante fonte de transmissão de informação, inclusive, suas características e principalmente, o papel desempenhado, veem sendo analisadas nos estudos de comunicação. A internet oferece um recurso capaz de atingir cada vez mais uma participação virtual ativa, bem como fortalecer o processo democrático (MAIA, 2000). 
Assim a internet é uma mídia no sentido restrito do termo, isto é, um suporte tecnológico para a comunicação, por mobilizar os recursos da escrita, imagem e som, em razão do caráter multimídia (MAIGRET, 2010).

\section{DISCUSSÃO}

As discussões a respeito do papel da internet giram em torno da sua representação como um novo espaço público capaz de promover o debate e propiciar a formação de opinião, sendo denominada por alguns autores como "democracia eletrônica" (GOMES, 2005; PEIXOTO, 2009; MAIA, 2000; FREIRE e SALES, 2010); ou então que a internet atua como um "subsistema político virtual" permitindo que a comunicação e a informação políticas mais inteligíveis e dinâmicas para com os cidadãos mais interessados (NORRIS, 2001) ou ainda, o seu uso concomitante pelos os outros meios (MAIGRET, 2010).

A internet cria um novo espaço de debate e formação de opinião, a este fenômeno dá-se o nome de democracia eletrônica:

\footnotetext{
Entende-se por democracia eletrônica o uso de Tecnologias da Informação e Comunicação (TICs) como meios para aumentar a transparência de processos políticos, facilitar a participação cidadã nos sistemas de tomada de decisão e, finalmente, melhorar a qualidade do processo de formação de opinião na esfera pública, a partir da abertura de novos espaços de informação e deliberação. (PEIXOTO, 2009, p. 2).
}

As relações sociais não estão mais limitadas à esfera local onde acontecem, elas são invariavelmente influenciadas pela cultura e expressão de indivíduos que estão em múltiplos lugares, uma vez que a rede permite a conexão imediata entre pessoas de dessemelhantes nacionalidades, sendo o tempo e distância entraves superados:

\footnotetext{
O outro não está mais necessariamente "ao nosso lado", face a face, na nossa vizinhança ou comunidade de bairro. Ele continua na proximidade local, mas está também distante, nas nossas relações eletronicamente mediadas em instrumentos da Web 2.0 como Facebook, Orkut, Twitter, Blogs, etc. As mídias, incluindo as atuais, ampliam nossa visão dos lugares (criando novos sentidos) e de nós mesmos por jogos de espelho ampliados e por relações com o "outro", ao mesmo tempo presencial e mediado. Cria-se, assim, "new sense of places" $e$ "new sense of selves" (LEMOS, 2010, p. 176/177).
}

Por este motivo a demanda por informações na internet é motivada pela praticidade, rapidez e comodidade de acesso tendo em vista que a linguagem digital permite 
que ela seja guardada, armazenada, recuperada, processada e transmitida, dinamizando o seu fluxo e alterando os modos de disseminar o conhecimento (BARBALHO, 2004, p. 1).

Para Maigret (2010, p. 409) os servidores de dados constituem ferramentas de busca, isto é, de consulta funcional da informação mais do que de comunicação. O e-mail é um instrumento de comunicação interpessoal, e os fóruns de debate servem como espaço de discussão e de trabalho em comum. A web transmite em parte conteúdos de tipos de meios de comunicação de massa ou mídias especializadas, pois alguns sítios informativos ou lúdicos preenchem funções próximas das revistas de papel, dos jornais, dos programas de televisão, da música produzida ao vivo.

Desta forma, meios de comunicação como jornais impressos, revistas, televisão, rádios, migram no todo ou em parte seu conteúdo para a internet. Assim, na percepção de Maigret (2010, p. 426) a imprensa de informação em geral disponibiliza online uma grande parte de suas edições diárias, sob pressão da concorrência, ao mesmo tempo em que traz algumas informações de última hora e debates. Fazendo isso, ela seduz os potenciais leitores do jornal impresso, cobra às vezes o acesso ao portal ou ainda, o acesso a determinados documentos e recebe lucros da publicidade colocada no portal.

O conceito de portal pode ser sintetizado como uma reunião de diversos serviços ofertados que foram agrupados de modo a possibilitar que, em um único endereço, o usuário pudesse encontrar uma variedade de opções que atendesse às suas necessidades e expectativas quando do acesso à rede (BARBALHO, 2004, p. 5).

Assim, sintetizando a contextualização a respeito das novas mídias, temos que estas acrescentam para o debate eleitoral, inclusive, é possível ver a utilização das novas mídias nas eleições atuais, sejam através dos portais informativos em plataforma web para a circulação de informações, sejam através de redes sociais (sites pessoais dos candidatos, facebook, twitter, instragram, dentre outros).

Além disso, nas eleições mais recentes, principalmente a partir de 2002 no Brasil, é possível identificar algumas mudanças nos processos decisórios com a introdução das novas tecnologias de comunicação e ferramentas de divulgação de informações políticas. Esses instrumentos foram apropriados pelos candidatos, mas também pelas grandes empresas de comunicação que, além de manterem os jornais impressos, passaram a disputar espaço na rede mundial de computadores. Dessa forma, os sites passam a ser considerados como nova plataforma de informação política que, junto com a mídia impressa e a televisão, ajudam a agendar as discussões na esfera pública. E embora muitos sites e portais surjam dentro de grandes grupos de comunicação - como é o caso do Estadão.com - o conteúdo pode ser diferenciado de acordo com as características da nova plataforma, do público alvo e das rotinas produtivas próprias dos veículos on-lines (MASSUCHIN \& CERVI, 2012, p. 3/4). 
Pelo exposto, temos que o papel dos meios de comunicação analisado através do papel das novas mídias, neste caso, o portal eletrônico Gazeta do Povo, contribui para compreender de que forma estes meios de comunicação alimentam o debate público, principalmente no período eleitoral, momento em que as eleitores acessam as informações transmitidas pelos meios noticiosos com o objetivo de decidir ou confirmar a escolha do voto.

Os meios de comunicação, portanto, representam uma ferramenta capaz de transmitir informações aos leitores, e para que esta relação seja democrática é necessário que aquilo que é repassado, seja feito de forma objetiva e imparcial, principalmente quando relacionado à cobertura eleitoral.

\section{OBJETO EMPÍRICO, METODOLOGIA E ANÁLISE DOS DADOS DO PORTAL GAZETA DO POVO}

A internet como meio de comunicação está diretamente ligada a realidade da sociedade, principalmente pela facilidade ao acesso e a maior interação com o usuário. Desta forma, muitos jornais impressos compartilham suas notícias através dos portais eletrônicos, possibilitando assim, uma maior gama de leitores, facilitando o acesso e a influência mútua.

Com o objetivo de analisar a cobertura das eleições municipais de Curitiba, para o ano de 2012, o portal eletrônico Gazeta do Povo foi o escolhido como instrumento de análise, por apresentar no caderno "Vida Pública" notícias, geralmente, relacionadas à campanha eleitoral, político institucional, economia, política social e infraestrutura, sendo que foram coletados apenas os textos que continham a citação de ao menos um candidato e que estivessem inseridos neste caderno fixo do Portal, excluindo textos de demais seções, mas podendo ser em modelo tanto opinativo quanto informativo se atendessem ao critério de inserção utilizado.

Como recorte da pesquisa a análise incidirá sobre os três principais candidatos à Prefeitura Municipal de Curitiba na disputa eleitoral, representados por Luciano Ducci (PSB), Gustavo Fruet (PDT) e Ratinho Jr. (PSC).

Para a análise dos dados será utilizado o método quantitativo, a utilização deste método tem como objetivo identificar como o assunto "campanha eleitoral" aparece nos jornais a partir de características que podem ser medidas e contabilizadas. Ainda no que 
tange a justificativa, Cervi explica que a escolha do método está diretamente relacionada ao objeto de análise:

O que justifica a utilização de instrumentos estatísticos e matemáticos na pesquisa quantitativa é que eles permitem reduzir uma grande massa de informações a alguns indicadores que são capazes de representar as principais características do objeto analisado (CERVI, 2013, p. 21).

Para a aplicação da metodologia quantitativa, através de determinadas variáveis, foi criado um livro de código específico "Análise de Conteúdo - Portais de Jornais/2012" pelo Grupo de Pesquisa em Comunicação Política e Opinião Pública - UFPR e pelo Núcleo de Pesquisa em Mídia, Política e Atores Sociais - UEPG. Dentro deste existiam diversas possibilidades de cruzamento de variáveis, além de múltiplas tipificações de temas, aqui foram subtraídas aquelas que continham maior grau explicativo no que se pretende descobrir, restou, então, uma vasta gama de variáveis a serem exploradas futuramente em demais trabalhos e questionamentos.

O universo coletado é de 378 posts, compreendendo o período de $1^{\circ}$ de julho de 2012 a 31 de outubro de 2012. A análise do volume da cobertura objetiva demonstrar qual a forma de tratamento que o portal deu para o tema eleição da Prefeitura Municipal de Curitiba, no período de julho a outubro de 2012. Na tabela que se segue foram escolhidos os temas que obtiveram maior quantificação no mês em que encontra-se inserido, existindo a diversidade dentre Esportes, Cultura e Lazer, Economia, Política Internacional etc.

TABELA 1 - DISTRIBUIÇÃO DOS TEMAS

\begin{tabular}{|c|c|c|c|}
\hline MÊS & TEMAS & FREQUÊNCIA & PERCENTUAL \\
\hline \multirow[t]{4}{*}{ Julho } & Campanha Eleitoral & 38 & 70,4 \\
\hline & Político-institucional & 10 & 18,5 \\
\hline & Ético-moral & 6 & 11,1 \\
\hline & Total & 54 & 100,0 \\
\hline \multirow[t]{4}{*}{ Agosto } & Campanha Eleitoral & 81 & 94,2 \\
\hline & Político-institucional & 3 & 3,5 \\
\hline & Ético-moral & 2 & 2,3 \\
\hline & Total & 86 & 100,0 \\
\hline \multirow[t]{6}{*}{ Setembro } & Campanha Eleitoral & 92 & 92,0 \\
\hline & Político-institucional & 4 & 4,0 \\
\hline & Política Social & 1 & 1,0 \\
\hline & Ético-moral & 2 & 2,0 \\
\hline & Cultura e variedades & 1 & 1,0 \\
\hline & Total & 100 & 100,0 \\
\hline
\end{tabular}




\begin{tabular}{l|l|l|l}
\hline \hline \multirow{3}{*}{ Outubro } & Campanha Eleitoral & 136 & 98,6 \\
\cline { 2 - 5 } & Político-institucional & 1 &, 7 \\
\cline { 2 - 5 } & Outros temas & 1 &, 7 \\
\cline { 2 - 4 } & Total & 138 & 100,0 \\
\hline \hline
\end{tabular}

FONTE: Núcleo de Comunicação Política e Opinião Pública - CPOP/UFPR.

Analisando a tabela 1 verifica-se que o tema predominante durante a cobertura foi Campanha Eleitoral, ou seja, fora voltada mais para o dia-a-dia da campanha dos candidatos, havendo pouca ênfase nos demais temas, inclusive, no político institucional. Isto pode significar que nos meses analisados desloca-se a atenção do que é o presente na Política para focar-se na Campanha em si, deixando de lado, inclusive, aspectos que, em tese, ainda importam no cotidiano do eleitor - já que ações políticas da gestão atual continuam a impactar suas vidas mesmo que pouco tempo antes das eleições- para apresentar de maneira abrangente o que se pode chamar de um diário dos acontecimentos, sejam eles banais e/ou surpreendentes, da Campanha.

No mês de julho, por exemplo, das 54 entradas, 38 destas se referiam ao tema campanha eleitoral, o que representa $70,4 \%$ de todas as chamadas dentro deste mês, os temas político institucional e ético moral juntos representam cerca de 30\% do total de chamadas. Já no mês de agosto o tema campanha eleitoral aparece em 81 das 86 chamadas, representando $94,2 \%$ do volume total deste mês, os temas político institucional e ético moral não chegam a $6 \%$ do total de chamadas no mês de agosto. No mês de setembro, das 100 chamadas, 92 destas se referem ao tema campanha eleitoral, ou seja, 92\% de todas as chamadas para o mês de setembro, e os temas político institucional, política social, ético moral e cultura representam $8 \%$ do volume total de chamadas. No mês de outubro das 138 entradas, 136 são do tema campanha eleitoral, ou seja 98,6\%, seguido de 1 entrada sobre o tema político institucional e 1 entra sobre outros temas.

Isto não representa uma descoberta extraordinária se levarmos em conta a função básica do jornalismo e dos meios de comunicação em ofertar em seus respectivos espaços uma arena segura para que sejam feitos os debates e mediações entre candidatos e eleitores. Logo, é esperando que ajam contribuições destes meios, quanto mais a nova dinâmica da internet, muito mais interativa que as demais, no que dizem respeito a formação de impulsos que propõe esta troca entre opinião pública e indivíduo. 
Em seguida, analisa-se o enquadramento dado pelo portal Gazeta do Povo que se divide em corrida de cavalos, personalista, temático e episódico. O enquadramento corrida de cavalos representa a evolução da campanha como uma corrida entre os candidatos, a ênfase está em quem está na frente e quem está atrás da disputa eleitoral, ligado, portanto, aos resultados das pesquisas e estratégias de campanha dos candidatos. $\mathrm{O}$ enquadramento personalista está ligado aos atores individuais, focaliza os eventos a partir dos dramas humanos, relegando considerações políticas e institucionais. O enquadramento temático designa os padrões interpretativos que enfatizam as posições e propostas dos candidatos sobre aspectos subjetivos da campanha. Neste aspecto, a ênfase das notícias que adotam esta perspectiva está nas plataformas e programas representados pelos diferentes candidatos. No enquadramento episódico, o jornalista se restringe a relatar os últimos acontecimentos sem a utilização dos enfoques que caracterizam os demais tipos de enquadramento (PORTO, 2001, p. 13/14).

Assim a tabela 2 que representa os enquadramentos dados pelo portal Gazeta do Povo se distribuiu da seguinte forma:

TABELA 2 - TIPO DE ENQUADRAMENTO

\begin{tabular}{|c|c|c|}
\hline ENQUADRAMENTO & FREQUÊNCIA & PERCENTUAL \\
\hline Corrida de cavalos & 17 & 4,5 \\
\hline Personalista & 8 & 2,1 \\
\hline Temático & 138 & 36,5 \\
\hline Episódico & 215 & 56,9 \\
\hline Total & 378 & 100,0 \\
\hline
\end{tabular}

FONTE: Núcleo de Comunicação Política e Opinião Pública - CPOP/UFPR.

O enquadramento predominante foi o episódico, com 215 entradas do total de 378 , o que representa $56,9 \%$ de todo o volume, seguido do enquadramento temático com 138 entradas, o que representa 36,5\%, corrida de cavalos com 17 entradas, representando $4,5 \%$ e personalista com 8 entradas, 2,1\% do total de chamadas.

Portanto, é possível verificar que o enquadramento mais encontrado nas postagens foi o episódico, geralmente relacionado aos últimos acontecimentos da cobertura eleitoral, como por exemplo, agenda de campanha, onde os candidatos estavam, debates, convenções, reuniões. No temático que apresentou 36,5\% do volume total, geralmente representava os programas e propostas apresentadas pelos candidatos. O enquadramento corrida de cavalos apresentou $4,5 \%$ do volume total e se referia geralmente aos resultados 
de pesquisa de opinião. O valor mais residual é do enquadramento personalista que apresentou 2,1\% do volume total, ou seja, houve poucas matérias que se fundamentaram na personalidade do candidato, o que significa que os textos tendem a focar mais na disputa eleitoral e muito pouco nos personagens.

Analisando a tabela 1 (distribuição dos temas) com a tabela 2 (tipo de enquadramento) verificamos que a cobertura realizada pelo portal Gazeta do Povo foi factual, porque preponderou o tema campanha eleitoral e o enquadramento predominante foi o episódico, demonstrando que o portal focou mais na agenda dos candidatos, do que propriamente nas propostas de governo ou até mesmo na atuação dos candidatos no Executivo e Legislativo, em virtude do Luciano Ducci ser candidato a reeleição e Gustavo Fruet e Ratinho Junior integrarem o legislativo.

Ainda neste contexto, foi possível verificar que o número de postagens de acordo com os meses coletados representou uma reta crescente conforme se aproximava com o dia das eleições. A maioria das postagens neste período se referiu ao tema campanha eleitoral, de modo que neste primeiro bloco, o portal Gazeta do Povo demonstrou ser factual.

No próximo bloco será analisado o volume da cobertura para cada um dos candidatos (Luciano Ducci, Gustavo Fruet e Ratinho Junior), para isto serão analisadas a visibilidade o número de citações no texto e a valência atribuída a cada candidato.

Para coletar a citação do candidato no texto, todas as matérias veiculadas no caderno "Vida Pública" foram visualizadas e verificado em quais destas matérias algum dos candidatos da disputa (Ducci, Fruet, e Ratinho Jr.) aparecia no texto pelo menos uma vez, caso aparecesse a citação era feita a coleta dos dados das postagens inteira. Conforme a tabela 3 a distribuição ficou a seguinte:

TABELA 3 - CITAÇÃO NO TEXTO

\begin{tabular}{l|l|l|l}
\hline \hline CANDIDATO & CITAÇÃO NO TEXTO & FREQUÊNCIA & PERCENTUAL \\
\hline \multirow{2}{*}{$\begin{array}{l}\text { LUCIANO } \\
\text { DUCCI }\end{array}$} & Sim & 242 & 64,0 \\
\cline { 2 - 4 } & Não & 136 & 36,0 \\
\cline { 2 - 4 } & Total & 378 & 100,0 \\
\hline \multirow{2}{*}{\begin{tabular}{l} 
FUUSTAVT \\
\cline { 2 - 4 }
\end{tabular}} & Sim & 281 & 74,3 \\
\cline { 2 - 5 } & Não & 97 & 25,7 \\
\cline { 2 - 4 } & Total & 378 & 700,0 \\
\hline RATINHO & Sim & 273 & 72,2 \\
\hline \hline
\end{tabular}




\begin{tabular}{l|l|l|l}
\hline \hline \multirow{2}{*}{ JUNIOR } & Não & 105 & 27,8 \\
\cline { 2 - 4 } & Total & 378 & 100,0 \\
\hline \hline
\end{tabular}

FONTE: Núcleo de Comunicação Política e Opinião Pública - CPOP/UFPR.

O candidato mais citado dentro das postagens é Gustavo Fruet com 281 citações de 378 chamadas, o que representa o montante de 74,3\%, seguido do Ratinho Junior com 273 citações, representando $72,2 \%$ e por último Luciano Ducci com 242 citações, o que representou 64\% das entradas. Ressalta-se, inclusive, que o candidato Gustavo Fruet é o mais citado nos textos, sendo este, inclusive, o vencedor do embate ao final do segundo turno, tornando-se o Prefeito oficial da cidade de Curitiba.

A visibilidade do texto e a quantidade de citações não são suficientes para aferir o tratamento dado ao candidato, é necessário reunir com a variável qualitativa da valência para verificar se as postagens falam bem ou mal do candidato quando comparado aos demais.

Assim, passemos com a tabela 4 a análise da valência atribuída a cada candidato, onde a tipificação em positiva significavam textos onde atribuições expressamente construtivas eram atreladas aos candidatos, o contrário ocorria quando optava-se por apontar como negativa a citação, ali estavam textos considerados destrutivos para a imagem do candidato, no caso da valência equilibrada o mesmo espaço para ataques era dado para defesas, tanto em forma de texto como de declaração.

TABELA 4 - VALÊNCIA DOS CANDIDATOS LUCIANO, GUSTAVO E RATINHO

\begin{tabular}{|c|c|c|c|c|}
\hline \multicolumn{2}{|c|}{ CANDIDATO } & \multirow{2}{*}{$\frac{\text { FREQUÊNCIA }}{7}$} & \multirow{2}{*}{$\begin{array}{l}\text { PERCENTUAL } \\
1,9\end{array}$} & \multirow{2}{*}{$\begin{array}{l}\text { PERCENTUAL } \\
\text { VÁLIDO } \\
2,9\end{array}$} \\
\hline LUCIANO & Positiva & & & \\
\hline \multirow[t]{6}{*}{ DUCCI } & Negativa & 35 & 9,3 & 14,5 \\
\hline & Neutra & 197 & 52,1 & 81,7 \\
\hline & Equilibrada & 2 &, 5 & 8 \\
\hline & Total & 241 & 63,8 & 100,0 \\
\hline & Ausente & 137 & 36,2 & \\
\hline & Total & 378 & 100,0 & \\
\hline \multirow{5}{*}{$\begin{array}{l}\text { GUSTAVO } \\
\text { FRUET }\end{array}$} & Positiva & 26 & 6,9 & 9,3 \\
\hline & Negativa & 30 & 7,9 & 10,7 \\
\hline & Neutra & 222 & 58,7 & 79,0 \\
\hline & Equilibrada & 3 & 8 & 1,1 \\
\hline & Total & 281 & 74,3 & 100,0 \\
\hline
\end{tabular}




\begin{tabular}{l|l|l|l|l}
\hline \hline \multirow{4}{*}{$\begin{array}{l}\text { RATINHO } \\
\text { JUNIOR }\end{array}$} & Ausente & 97 & 25,7 & \\
\cline { 2 - 5 } & Total & 378 & 100,0 & \\
\cline { 2 - 5 } & Nositiva & 25 & 6,6 & 9,2 \\
\cline { 2 - 5 } & Negativa & 33 & 8,7 & 12,1 \\
\cline { 2 - 5 } & Equitra & 212 & 56,1 & 77,7 \\
\cline { 2 - 5 } & Total & 3 &, 8 & 1,1 \\
\cline { 2 - 5 } & Ausente & 105 & 72,2 & 100,0 \\
\cline { 2 - 5 } & Total & 378 & 27,8 & \\
\hline \hline
\end{tabular}

FONTE: Núcleo de Comunicação Política e Opinião Pública - CPOP/UFPR.

A análise da valência atribuída aos candidatos, conforme tabela 4, divide-se em: positiva, negativa, neutra e equilibrada. A análise da valência é importante porque constitui uma maneira de valorização dada pelo portal Gazeta do Povo que define grande parte do impacto da cobertura eleitoral.

No caso concreto o portal Gazeta do Povo foi predominantemente neutro no que concerne às valências. Todavia, é possível analisar as demais amostras (positivo, negativo e equilibrado) para a análise. Deste modo, verifica-se que o candidato Luciano Ducci apresentou $81,7 \%$ das valências neutras, $2,9 \%$ de valências positivas, $14,5 \%$ de valências negativas e $0,8 \%$ de valência equilibrada, observa-se neste caso que embora pese a valência neutra seja esta a preponderante para todos os candidatos, a valência negativa do Ducci é maior que a dos outros dois candidatos, ou seja, Luciano Ducci possui uma quantidade menor de citações ao longo do texto e apresenta mais valências negativas que os demais candidatos. Nota-se que Fruet e Ratinho apresentaram uma valência positiva muito parecida, em contrapartida Ducci apresentou um positivo muito baixo, principalmente quando comparado aos outros dois candidatos.

O candidato Gustavo Fruet apresenta $79 \%$ das valências neutras, 10,7\% das valências negativas e 9,3\% das valências positivas, traçando um comparativo com o Luciano Ducci o candidato Gustavo Fruet apresentou índices menores na valência neutra e negativa, porém, apresentou um índice maior em relação à valência positiva.

Quanto ao candidato Ratinho, este apresentou 77,7\% de valência neutra, 12,1\% de valência negativa e 9,2\% de valência positiva. Denota-se que Gustavo Fruet e Ratinho apresentaram valências positivas muito próximas, havendo apenas uma pequena diferença 
quanto à valência negativa. Ainda assim, a valência positiva de Gustavo e Ratinho é aproximadamente três vezes maior que a de Luciano Ducci.

Deste modo, observa-se que a predominância do portal Gazeta do Povo quanto à valência é neutra, entretanto, observando as demais variáveis, já que a valência neutra é quase sempre o resultado em quase todos os meios de comunicação, passando a importar, então as demais opções para traçado assertivo, é possível constatar que os candidatos Gustavo e Ratinho apresentam resultados na valência muito próximos, ao contrário de Ducci que possui resultados distantes dos outros candidatos, mais uma vez um resultado que coincide com aqueles expressos nos resultados das urnas, surpreende a então exacerbada atribuição negativa direcionada a Ducci, já que este era candidato da situação, levando a crer que as críticas podem ser provenientes tanto da sua capacidade como candidato quanto como gestor.

Importante ressaltar ainda neste contexto que, em que pese o foco desta pesquisa, a análise das valências demonstrou que a neutralidade é observada tanto no meio impresso (jornal), quanto no virtual (portal), conforme dados já coletados pelo Núcleo de Comunicação Política e Opinião Pública. Isto contraria a percepção de que as matérias veiculadas na internet possuem uma variação mais negativa, tendo em vista que há menos controle. Resultados de uma pesquisa realizada pelo mesmo núcleo denominada "a relação entre a cobertura eleitoral do Jornal Gazeta do Povo e o resultado da eleição municipal da cidade de Curitiba, ano de 2012" (LOPES, 2013) demonstram que a valência neutra atingiu todos os picos para os três candidatos, também no ano de 2012, na versão impressa do mesmo jornal.

\section{CONCLUSÃO}

O artigo possui um caráter descritivo da cobertura eleitoral dada pelo portal Gazeta do Povo para as eleições municipais de Curitiba no ano de 2012, analisando os candidatos com as maiores votações, Gustavo Fruet, Ratinho Junior e Luciano Ducci. Não se objetivou durante a pesquisa realizar um comparativo entre um portal e outro, ou entre o portal e uma mídia impressa, porque acredita-se que o recorte sendo exclusivamente para o portal permitiria verificar como este meio que vem sendo utilizado com frequência pelos curitibanos tratou do tema eleições. Frisa-se que todo o universo a respeito das eleições, bem como pela cobertura dada pela mídia não se esgotam nesta pesquisa. 
Verificou-se que o Portal Gazeta do Povo apresentou 378 postagens entre os meses de julho a outubro, sendo que estes números cresceram com a proximidade das eleições. O tema preponderante foi a campanha eleitoral, demonstrando que a cobertura dada pelo Portal Gazeta do Povo foi satisfatória e coerente com a importância políticosocial do acontecimento eleitoral do período.

O enquadramento dado pelo portal Gazeta do Povo foi predominantemente episódico, ou seja, tratou mais de fatos das rotinas dos candidatos, do que a respeito das promessas de campanha ou políticas públicas.

No quesito visibilidade no texto o candidato Gustavo é o mais citado no corpo do texto, seguido de Ratinho e por último Luciano Ducci. Verifica-se que, em que pese Luciano Ducci seja candidato à reeleição, teve pouca visibilidade quando comparado aos outros dois candidatos, estes por sua vez, apresentaram visibilidades semelhantes no texto, não à toa Ratinho e Fruet foram os candidatos com maior número de votos e que seguiram, assim, para um segundo turno na campanha.

Assim, tendo em vista que a variável visibilidade pouco acrescentou para acatar ou não a hipótese, analisou-se a valência dos candidatos. De início, observou-se que o portal Gazeta do Povo foi predominantemente neutro em suas postagens, ou seja, não fazia juízo de valor (positivo ou negativo) sobre determinado candidato. Porém as variáveis positivas e negativas apresentaram valores dignos de serem analisados, sendo que a valência negativa foi semelhante aos três candidatos porque apresentaram a seguinte ordem: Luciano Ducci com uma frequência de 35, seguido de Ratinho Junior com 33 e Gustavo Fruet com 30. Na valência positiva, por sua vez, os candidatos Gustavo Fruet e Ratinho Junior apresentaram valores muito próximos, Gustavo com 26 e Ratinho Junior com 25, todavia Luciano Ducci apresentou uma valência positiva muito baixa, com o percentual de 1,9\%. Deste modo, até o momento se verifica que a cobertura dada aos candidatos Gustavo Fruet e Ratinho Junior foram muito semelhantes, a diferença reside no candidato Luciano Ducci, que teve um espaço menor no portal, com a menor valência positiva e a maior valência negativa quando comparado aos outros candidatos.

$\mathrm{Na}$ análise da valência de cada candidato comparado com o mês, verificou-se que Luciano Ducci apresentou mais valências negativas do que positivas. Gustavo Fruet também apresentou mais valências negativas, porém a diferença entre positiva era mais próxima (30 valências negativas e 26 positivas). Ratinho Junior também apresentou mais valências negativas, porém, a mesma lógica aplicável ao Fruet cabe aqui, tendo em vista que 
a diferença de valência negativa para a positiva foi pequena (apresentou 25 valências positivas).

Assim, pode-se concluir que não houve grandes diferenças no tratamento dos candidatos pelo portal Gazeta do Povo, mas que em particular ao candidato Ducci fora direcionada maior crítica, vide sua valência negativa. É importante ressaltar que, não pautando a discussão clássica entre a dinâmica de Sociedade x Agendamento Midiático, há congruência no que é exposto no Portal e o que é explícito nas urnas, em sequência, na mesma ordem decrescente do índice de valência positiva, Fruet, seguido por Ratinho e Ducci foram os três primeiros colocados nas eleições. Ratinho Jr. também é caso exemplificador da relação entre visibilidade e valência serem complementares, já que recebe maior visibilidade, mas também maior atribuição negativa que Fruet.

A partir da análise descritiva feita aqui, destaca-se que esta análise não pretende medir se estes resultados contribuíram ou não para os resultados obtidos nas urnas, porque para isto, outras análises seriam precisas, os resultados desta pesquisa demonstram como o portal Gazeta do Povo levou a informação até os eleitores. Todavia, verifica-se que o Portal Gazeta do Povo abrangeu factualmente a cobertura eleitoral da Prefeitura Municipal de Curitiba e demonstrou que a internet vem representando este novo espaço de informação e acessibilidade que contribuem para que o eleitor escolha o candidato.

\section{REFERÊNCIAS BIBLIOGRÁFICAS}

AZEVEDO, F. 2004. Agendamento da Política. In: Rubim, A. \& AZEVEDO, F (org.). Comunicaşão Politica: Conceitos e abordagens. Salvador: Edufba.

BARBALHO, C. R. S. 2004. Portais eletrônicos: estudo comparativo da oferta em Comunicação. XVI ENDOCOM - Encontro de Informação em Ciências da Comunicação, 1-15.

CERVI, E. 2013. Métodos quantitativos aplicados às Ciências Sociais. UFPR.

LEMOS, A. 2010. Caderno de Viagem: Comunicação, Lugares e Tecnologias. Porto Alegre: Editora Plus. 2010. 
LOPES, L. 2012. Visibilidade de temas politicos na sociedade de informação: uma análise das eleições municipais de 2012, em Curitiba, sob o enfoque das primeiras páginas e cadernos internos do jornal Gaz̧eta do Povo. Evento de Iniciação Científica - EVINCI, 2013.

MAIGRET, E. 2010. Sociologia da comunicação e das mídias. São Paulo: Editora Senac.

MANIN, B. 1995. As Metamorfoses do Governo Representativo. Revista Brasileira de Ciências Sociais, no 29, ano 10.

MASSUCHIN, M. G., \& CERVI, E. U. 2012. Novas plataformas e meios tradicionais: sinergia on antagonismo? Uma análise exploratória entre a cobertura presidencial de 2010 no jornal diário O Estado de São Paulo e no portal Estadão.com. 36o Encontro Anual da ANPOCS.

MCCOMBS, M.; SHAW, D. 1972. The agenda-setting function of mass media. Public Opinion Quaterly, New York, vol. 36, nº 2, pp. 176-187.

MIGUEL, L. F. 2000. Um ponto cego nas teorias da democracia: os meios de comunicação. Revista Brasileira de Informação Bibliográfica em Ciências Sociais. BIB, Rio de Janeiro, n.49.

NORRIS, P. 2001. Digital divide?: civic engagement, information poverty, and the Internet Worldwide. Cambridge: Cambridge University Press.

PORTO, M. 2001. A mídia brasileira e a eleição presidencial de 2000 nos EUA: a cobertura do jornal Folha de São Paulo, Cadernos do CEAM. Ano II, n. 6. 